\title{
Abdominal mass in a 19-year-old with neurofibromatosis
}

\author{
Isaac Samuel, Shriram Jakate, Michael M Ramsey, Theodore J Saclarides
}

A 19-year-old white man with known von Recklinghausen's neurofibromatosis developed anorexia and abdominal pain associated with a mobile lower abdominal mass. Characteristic caféau-lait spots and subcutaneous neurofibromas were present. Other features associated with von Recklinghausen's disease ${ }^{1-4}$ included mental retardation, a history of headaches and seizures, and scoliosis. Magnetic resonance imaging (MRI) showed a tubular mass $3 \times 7 \times 8 \mathrm{~cm}$ in the lower abdomen (figure 1). A diagnostic laparoscopy was performed (figure 2).
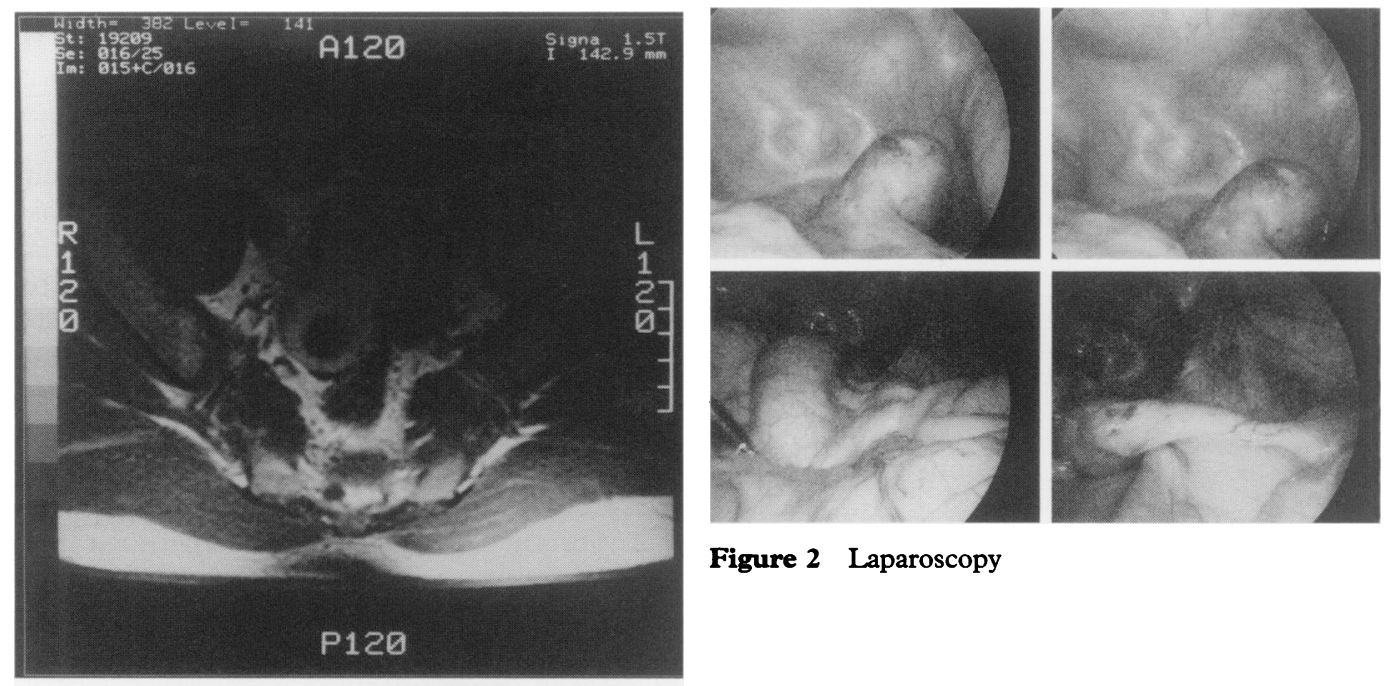

Figure 2 Laparoscopy

Rush-Presbyterian St Luke's Medical Center and Rush Medical College, 1653 West Congress Parkway, Chicago, IL 60612, USA Department of General Surgery I Samuel

TJ Saclarides

Department of Pathology

S Jakate

Department of Internal Medicine MM Ramsey

Correspondence to Dr Theodore Saclarides

Accepted 10 May 1996

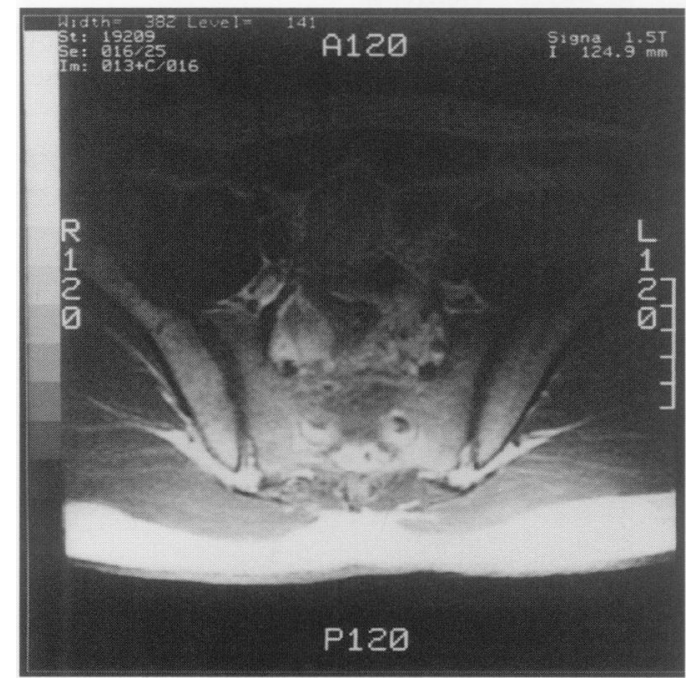

Figure 1 MRI scan of abdomen

\section{Questions}

1 What is the most likely cause of the abdominal mass?

2 What is the risk of malignant transformation associated with neurofibromastosis? 


\section{Answers}

\section{QUESTION}

Neurofibroma of the appendix. This was confirmed by an open appendicectomy.

\section{QUESTION 2}

The risk of sarcomatous change in neurofibromas is about $15 \% .^{3}$

\section{Gastrointestinal involvement in neurofi- bromatosis}

Neurofibromas in patients who do not have von Recklinghausen's disease, although often multiple, are not associated with cafe-au-lait spots. ${ }^{1}$ Approximately $25 \%$ of patients with von Recklinghausen's neurofibromatosis have or develop gastrointestinal neurofibromatosis, while only about $15 \%$ of those with neurofibromas arising in the gastrointestinal tract are associated with von Recklinghausen's disease. $^{2-4}$ Gastrointestinal neurofibromas most often occur in the small intestine, followed by the stomach, while involvement of the colon and appendix is infrequent. ${ }^{3,4}$ Presenting features of gastrointestinal neurofibromatosis have included symptoms such as abdominal pain, haematemesis, haematochezia and melaena, or complications such as gastrointestinal obstruction, perforation, intussusception, and volvulus formation. ${ }^{3,4}$

\section{Discussion}

Von Recklinghausen's neurofibromatosis is an autosomal dominant disorder with variable penetration, characterised by multiple neurofibromas and café-au-lait spots. ${ }^{1}$ To the best of our knowledge, only eight cases of appendiceal neurofibromatosis have previously been reported in the literature; of these, six were associated with von Recklinghausen's neurofibromatosis, and two were examples of solitary appendiceal neurofibroma not associated with von Recklinghausen's disease. ${ }^{2}$ In previous reports, appendiceal neurofibromatosis has

1 Riccardi VM, Von Recklinghausen neurofibromatosis. $N$ Engl f Med 1981; 305: 1617-27.

2 Olsen BS. Giant appendicular neurofibroma. A light and immunohistochemical study. Histopathology 1987; 11: 851 5.

3 Davis GB, Berk RN. Intestinal neurofibromas in von Recklinghausen's disease. Am $\mathcal{f}$ Gastroenterol 1973; 60: 410-4.

\section{Neurofibromatosis}

Essential features:

- multiple neurofibromatosis

- café-au-lait spots, six or more, measuring at least $1.5 \mathrm{~cm}$

Associated features:

- headache

- seizures

- mental retardation

- Lisch nodules (pigmented iris hamartomas)

- macrocephaly

- central nervous system tumours

- pseudarthrosis

- kyphoscoliosis

- short stature

- sarcomatous malignant transformation

- medullary carcinoma of the thyroid

- phaeochromocytoma

- hypertension

- constipation

- pruritus

presented as a palpable mass or with acute appendicitis, or has remained asymptomatic. ${ }^{2}$ Although abdominal pain was a feature in the present report, histopathologic examination of the appendix failed to reveal acute appendicitis. The initial laparoscopic approach was converted to an open appendectomy since, if this were a malignant mucocele, possible spillage induced by the laparoscopic instrument could be avoided. Although appendiceal involvement is rare, it should be considered in the differential diagnosis of lower abdominal pain in patients with multiple neurofibromatosis.

\section{Final diagnosis}

Appendiceal neurofibromatosis in von Recklinghausen's disease.

Keywords: appendix, neurofibromatosis, von Recklinghausen's disease

4 Hochberg FH, Dasilva AB, Galdabini J, Richardson EP. Gastrointestinal involvement in von Recklinghausen's neurofibromatosis. Neurology 1974; 24: 1144-51. 